Peter M. Suter

\title{
Some ICUs save more lifes than others: we need to know why!
}

Received: 13 September 2005

Accepted: 13 September 2005

Published online: 29 September 2005

(C) Springer-Verlag 2005

This editorial refers to the articles http://dx.doi.org/10.1007/ s00134-005-2762-6 and http://dx.doi.org/10.1007/s00134-0052763-5

P. M. Suter $(\bullet)$

Service des Soins Intensifs de Chirurgie, University Hospitals of Geneva,

Rue Michel-du-Crest 24, 1211 Geneva 14, Switzerland

e-mail: Peter.suter@rectorat.unige.ch

For 25 years the early prediction of hospital mortality has been investigated extensively in ICU patients. Assessment of preexisting morbidities and acute physiological derangements have resulted in risk-adjusted outcomes allowing patient classification according to severity of disease. This permitted the effects of different treatment regimens to be compared more appropriately by taking into account the presence of chronic disease states together with the importance of acute organ dysfunction at the beginning of therapy. In addition, comparison of outcome with risk adjustment has also been attempted between different ICUs and between countries [1]. The first generation of these severity scores was published more than 20 years ago-APACHE I and II, SAPS I in 1981-1985 [2, 3, 4]-followed by the second generation 10 years later-APACHE III, SAPS II, MPM II in 1991$1993[1,5,6]$. Ten years later the third generation of these tools is knocking at the door. In Intensive Care Medicine Metnitz, Moreno, and their colleagues [7, 8] now report on the promising SAPS 3 system.

Including almost 20,000 patients from several hundred ICUs from all continents, this article reports the largest investigation of this type yet conducted. As we would expect, patient populations are heterogeneous, and cer- tainly ICU organization, staffing, and resources between East and West, North, and South. Not unexpectedly, prognostic performance of an earlier but widely used predictive score for mortality, SAPS II, was poor. This was true for the overall cohort and a majority of the seven regions of the world. The new SAPS 3 ICU admission score seems to be much better suited to predicting vital status at hospital discharge. Customized equations were established for specific areas of the globe, providing a real possibility to evaluate the ICU. Therefore this study provides data not only on outcome of patients representing a very wide range of pathologies requiring intensive care but also on widely differing countries, thereby giving food for thought on many questions in the field of evaluation of medical care. For instance, are the differences in mortality between different continents, as well as within Europe, real or do they merely reflect different patient populations, comorbidities, or different therapies?

Where are we going from here? Many health care specialists are convinced that quality assessment will be an essential part of tomorrow's management strategies in all hospitals. This seems particularly valid for the most expensive areas, including a number of high-tech and personnel-intensive domains such as intensive care. Transparent, objective, and precise evaluation systems of care strategies taking into account risk adjustment and providing outcome estimation will undoubtedly be part of the future, and for several reasons: First, health care providers and society want to know on what basis important investments of resources are warranted in certain situations. Second, the ICU team will request precise benchmarks, not only to test alternative therapeutic approaches but also to evaluate the effects of novel organizational and management strategies. Tools such as SAPS 3 could help in the assessment of potentially rewarding changes. Third, the differences observed in the present investigations between different regions-and certainly also between different ICUs in the same country or continent-constitutes an interesting data pool which 
must be analyzed further. This could help to elucidate which elements are associated with these differencesmost probably hospital type, and case mix, and resources but perhaps also team organization and function, professional experience, and coverage.

More than 300 ICUs have contributed to the enormous amount of cross-checked and reliable data collected, al- lowing robust conclusions. Let us not stop here. The merit of the most interesting and valuable studies is not only their producing impressive results but their stimulating further questions and research. SAPS 3 is one of those remarkable clinical investigations - and we need to know more about how to make all our ICUs more efficient.

\section{References}

1. Le Gall JR, Lemeshow S, Saulnier F (1993) A new simplified acute physiology score (SAPS II) based on a European/North American multicenter study. JAMA 270:2957-2963

2. Knaus WA, Zimmermann JE, Wagner DP, Draper EA, Lawrence DE (1981) APACHE-acute physiology and chronic health evaluation: a physiologically based classification system. Crit Care Med 9:591-597

3. Le Gall JR, Loirat P, Alperovitch A (1983) Simplified acute physiological score for intensive care patients. Lancet II:741

4. Knaus WA, Draper EA, Wagner DP, Zimmermann JE (1985) APACHE II: a severity of disease classification system. Crit Care Med 13:818-829
5. Knaus WA, Wagner DP, Draper EA, Zimmermann JE, Bergner M, Bastos PG, Sirio CA, Murphy DJ, Lotring T, Damiano A et al (1991) The APACHE III prognostic system. Risk prediction of hospital mortality for critically ill hospitalized adults. Chest 100:16191636

6. Lemeshow S, Teres D, Klar J, Avrunin JS, Gehlbach SH, Rapoport J (1993) Mortality Probability Models (MPM II) based on an international cohort of intensive care unit patients. JAMA 270:2478-2486
7. Metnitz PGH, Moreno RP, Almeida E, Abizanda Campos R, Iapichino G, Edbrooke D, Capuzzo M, Le Gall JR,

Jordan B (2005) SAPS 3 - From evaluation of the patient to evaluation of the intensive care unit. Part 1: Objectives, methods and cohort description. Intensive Care Med (DOI: http://dx.doi.org/ 10.1007/s00134-005-2762-6)

8. Moreno RP, Metnitz PGH, Almeida E, Abizanda Campos R, Iapichino G, Edbrooke D, Capuzzo M, Le Gall JR, Jordan B (2005) SAPS 3 - From evaluation of the patient to evaluation of the intensive care unit. Part 2: Development of a prognostic model for hospital mortality at ICU admission. Intensive Care Med (DOI: http://dx.doi.org/ 10.1007/s00134-005-2763-5) 